\title{
The Effects of Infant Massage on Maternal Distress: A Systematic Review
}

\author{
Michael Galanakis ${ }^{1,2}{ }^{*}$, Eleftheria Ntaouti², Georgios Tsitsanis ${ }^{2}$, George P. Chrousos ${ }^{2,3}$ \\ ${ }^{1}$ Panteion University of Social and Political Sciences, Athens, Greece \\ ${ }^{2}$ Postgraduate Course Science of Stress and Health Promotion, School of Medicine, University of Athens, \\ Athens, Greece \\ ${ }^{3}$ First Department of Pediatrics, Children's Hospital Aghia Sofia, School of Medicine, University of Athens, \\ Athens, Greece \\ Email: "galanakismichael@hotmail.com
}

Received 30 September 2015; accepted 26 December 2015; published 29 December 2015

Copyright (C) 2015 by authors and Scientific Research Publishing Inc.

This work is licensed under the Creative Commons Attribution International License (CC BY). http://creativecommons.org/licenses/by/4.0/

C) (7) Open Access

\begin{abstract}
Massage therapy is one of the oldest touch therapies, and it has been used for many conditions. We have systematically reviewed articles on infant massage to evaluate its effects on maternal distress, and also on mother-infant relationship. Infant massage has been known to benefit mothers and infants regarding several health variables such as depression, parenting stress, weight gain for the infant, hormones and anxiety as well as functionality of the immunity system. However, tactile-only stimulation must be distinguished from multisensory interventions that include a tactile component, for tactile-only stimulation without social contact is associated with higher levels of stress, and it is also overstimulating for infants. The significance of this systematic review lies in the important role of massage therapy in human health, as it highlights a crucial yet often underestimated effect in psychological and biosomatical variables.
\end{abstract}

\section{Keywords}

Infant Massage, Maternal Distress, Systematic Review

\section{Introduction}

Massage therapy (also known as tactile/kinesthetic stimulation) is one of the oldest touch therapies; it has been variously used for many conditions, such as mental illness, spasm, labor pain, delivery, postpartum bleeding and others (Field, 1995). Massage has also been used for stimulation of the breast for milk, for speeding healing

${ }^{*}$ Corresponding author. 
postsurgery, for rheumatic diseases, and generally, it is thought to improve circulation, reduce swelling, and soothe the peripheral and central nervous system (Field, 1995).

Another use of massage therapy is with infant-mother dyads; mothers of preterm infants (normal preterm infants, very preterm, brain-injured preterm infants) (Field, 1995; Holditch-Davis et al., 2014; Matricardi, Agostino et al., 2013; White-Traut, 2004), asthmatic children (Field, 1995), diabetic children (Field, 1995), infants prenatally exposed to illicit substances (Field, 1995; Wheeden et al., 1993; White-Traut, 2004), and also adolescent mothers (Oswalt et al., 2009) are often affected by distress (anxiety, depressive symptoms, post-traumatic stress symptoms, parenting stress) due to several reasons such as the loss of maternal role during infant hospitalization and worrying about infant health or survival (Holditch-Davis et al., 2014; Matricardi et al., 2013), separation from their child (White-Traut, 2004), giving birth in dangerous settings such as war and natural disasters (White-Traut, 2004), combined stress of adolescence, parenthood, maintaining peer relationships, as well as establishing positive relationships with their infants (Oswalt et al., 2009). Data from several studies relative to maternal distress and infant massage indicate benefits on mothers and their infants, such as lower levels of parenting stress and decline in depressive symptoms in mothers (Field, 1995; Holditch-Davis et al., 2014; Matricardi et al., 2013; Oswalt et al., 2009; White-Traut, 2004), as well as increased alertness before and after feedings, better weight gain, more responsiveness during mother-infant interactions, alleviation of motor problems, lower anxiety and stress hormones, improved immune function and earlier hospital discharge (preterm infants), among others, for the infants (Field, 1995; Holditch-Davis et al., 2014; Matricardi et al., 2013; Oswalt et al., 2009; Wheeden et al., 1993; White-Traut, 2004).

In this systematic review, studies relative to the effects of infant massage on maternal distress, and on various conditions were included. Four studies were randomized controlled trials (RCTs) (Holditch-Davis et al., 2014; Matricardi et al., 2013; Oswalt et al., 2009; Wheeden et al., 1993), and two were reviews (Field, 1995; WhiteTraut, 2004). The 4 RCTs will be discussed separately.

\section{Method}

\subsection{Search Strategy}

Electronic search was conducted in PubMed heading "Maternal Stress and Infant Massage". We focused on articles from 1990 to 2015. We emphasized on the appearance of both "stress" and "infant massage" in the article title or in the keywords. Studies that investigated the role of infant massage on different variables other than stress were omitted. We also had a strong preference for randomized clinical trials. The subject of infant massage and massage therapy in general is not very common in the literature. The 6 studies that have been analyzed in the present study are the ones that were found according to the above mentioned selection criteria.

\subsection{Selection of Eligible Trials}

RCTs that evaluated the intervention of infant massage on maternal distress were included, as were all other studies on infant massage in relation to mother-infant relationship, cocaine-exposed preterm infants, healthy infants and their parents, depressed mothers, grandparent volunteers as massage therapists, asthmatic children and their parents, and children with diabetes and their parents.

\section{Results}

The results of searching the PubMed electronic database were 11 articles. Among the 11 articles reviewed, 5 RCTs were identified that met the criteria of the Cochrane Central Register of Controlled Trials, but 1 of them was excluded by reason of language, which was Chinese (Table 1) (Holditch-Davis et al., 2014; Matricardi et al., 2013; Oswalt et al., 2009; Wheeden et al., 1993). 2 of the above mentioned RCTs were articles on parent-administered multisensory interventions for preterm infants (Holditch-Davis et al., 2014; Matricardi et al., 2013), 1 RCT article set out the effects of a massage intervention on teen mothers (Oswalt et al., 2009), and the fourth RCT described the effects of a massage therapy on cocaine-exposed preterm neonates (Wheeden et al., 1993). Another 4 articles were also excluded on account of incompatibility with the subject of the review. The last 2 articles were reviews of multisensory interventions for infants and children in adverse situations (e.g. 
Table 1. Characteristics of Cochrane RCTs.

\begin{tabular}{|c|c|c|c|c|}
\hline & Holditch-Davis et al. ${ }^{1}$ (2014) & Matricardi et al. ${ }^{2}$ (2013) & Oswalt et al. ${ }^{3}$ (2009) & Wheeden et al. $^{6}$ (1993) \\
\hline Interventions & $\begin{array}{l}\text { ATVV vs KC vs Control } \\
\text { group }\end{array}$ & $\begin{array}{l}\text { Intervention group (joint } \\
\text { observation method, infant } \\
\text { massage provided by both } \\
\text { parents) vs Standard } \\
\text { support group }\end{array}$ & $\begin{array}{l}\text { Massage intervention group } \\
\text { vs } \\
\text { Control group }\end{array}$ & $\begin{array}{l}\text { Massage therapy group } \\
\text { vs } \\
\text { Control group }\end{array}$ \\
\hline No of participants & $\begin{array}{l}240 \text { infant-mother dyads } \\
(\mathrm{ATVV} \rightarrow \mathrm{N}=78, \\
\mathrm{KC} \rightarrow \mathrm{N}=81 \text { and Control } \\
\text { group } \rightarrow \mathrm{N}=81 \text { ) }\end{array}$ & $\begin{array}{l}42 \text { parent-infant dyads } \\
\text { (intervention group } \rightarrow \mathrm{N}=21 \text {, } \\
\text { standard support group } \rightarrow \\
\mathrm{N}=21 \text { ) }\end{array}$ & $\begin{array}{l}25 \text { infant-mother dyads } \\
\text { (massage intervention group } \rightarrow \\
N=9 \text {, } \\
\text { control group } \rightarrow \mathrm{N}=16 \text { ) }\end{array}$ & $\begin{array}{l}30 \text { cocaine-exposed } \\
\text { preterm neonates } \\
\text { (massage therapy } \\
\text { group } \rightarrow \mathrm{N}=15 \text {, } \\
\text { control group } \rightarrow \mathrm{N}=15 \text { ) }\end{array}$ \\
\hline Study duration & $\begin{array}{l}\text { During hospitalization until } 12 \\
\text { months of age }\end{array}$ & $\begin{array}{l}\text { During the first week of life } \\
\text { until the } 36^{\text {th }} \text { week } \\
\text { post-menstrual age of the } \\
\text { infant }\end{array}$ & $\begin{array}{l}\text { Approximately } 2 \text { months and } \\
2 \text {-month follow-up measures }\end{array}$ & $\begin{array}{l}10 \text { days (massage } \\
\text { therapy was provided for } \\
\text { three } 15 \text {-minute periods for } \\
\text { three consecutive hours } \\
\text { each day) }\end{array}$ \\
\hline Effect size & $\begin{array}{l}\text { No change among the groups } \\
\text { on any maternal distress } \\
\text { variable. } \\
\text { Infant social } \\
\text { behaviors } \rightarrow \text { significant } \\
\text { overall intervention effect } \\
\text { ( } p<0.05 \text { ), but neither } \\
\text { ATVV nor KC differed } \\
\text { from the Control group. } \\
\text { Infant Developmental } \\
\text { maturity } \rightarrow \text { significant } \\
\text { overall intervention effect } \\
\text { ( } p<0.01 \text { ), KC was higher } \\
\text { than the other groups } \\
\text { ( } p<0.05 \text { ). } \\
\text { Mothers who performed a } \\
\text { form of massage } \rightarrow \text { more } \\
\text { rapid decline in depressive } \\
\text { symptoms ( } p<0.05 \text { ). } \\
\text { Mothers who performed } \\
\text { either a form of massage } \\
(p<0.05 \text { ) or both } \\
\text { interventions } \\
(p<0.05) \rightarrow \text { higher HOME } \\
\text { scores than mothers who } \\
\text { engaged in neither. } \\
\text { Parenting stress } \rightarrow \text { lower } \\
\text { for mothers engaged in any } \\
\text { intervention than those who } \\
\text { did not (a form of massage } \\
\text { only } \rightarrow p<0.001, \text { KC only } \rightarrow \\
p<0.01, \text { both } \rightarrow p<0.01 \text { ). }\end{array}$ & $\begin{array}{l}\text { At discharge: Intervention } \\
\text { group parents } \rightarrow \text { significantly } \\
\text { lower levels of stress } \\
\text { related to infant's } \\
\text { appearance/ } \\
\text { behaviour and to Parental } \\
\text { Role Alteration (PRA) } \\
\text { than those of the } \\
\text { Standard support group } \\
\text { ( } p=0.000) \text {. } \\
\text { Mothers } \rightarrow \text { more stress in } \\
\text { comparison with fathers } \\
\text { ( } p \leq 0.05 \text { ). } \\
\text { The intervention } \rightarrow \\
\text { effective in the reduction } \\
\text { of stress-role alteration in } \\
\text { mothers ( } p<0.05 \text { ), } \\
\text { but not in fathers. }\end{array}$ & $\begin{array}{l}\text { No significant difference } \\
\text { between intervention and } \\
\text { control groups in maternal } \\
\text { confidence, parental stress, or } \\
\text { ongoing feelings about } \\
\text { physical contact with people. } \\
\text { Teen mothers in the intervention } \\
\text { group (after the massage } \\
\text { intervention) } \rightarrow \text { more positive and } \\
\text { comfortable feelings about } \\
\text { physical contact with their current } \\
\text { relationships in comparison with } \\
\text { those in the control group } \\
\text { ( } p<0.05 \text { ). The massage } \\
\text { intervention exhibited a medium } \\
\text { effect size on feelings of physical } \\
\text { contact with current relationships } \\
\text { (d = 0.59). } \\
\text { Teen mothers trained in infant } \\
\text { massage } \rightarrow \text { significantly lower } \\
\text { depression scores than teen } \\
\text { mothers without massage training } \\
\text { ( } p<0.05 \text { ). A large effect size of } \\
\text { massage intervention was found for } \\
\text { both depression and maternal } \\
\text { confidence ( } d=0.91 \text { and } 1.10 \text { ). } \\
\text { Teen mothers in the intervention } \\
\text { group reported significantly more } \\
\text { adaptive temperament of their } \\
\text { infant than those in the control } \\
\text { group ( } p<0.05 \text { ). } \\
\text { The massage intervention exhibited } \\
\text { a large effect size on parental stress, } \\
\text { maternal perception of infant } \\
\text { temperament, and positive feelings } \\
\text { related to physical contact } \\
\text { (d = 0.92, } 1.34 \text {, and 0.62). }\end{array}$ & $\begin{array}{l}\text { Improvement in } \\
\text { orientation behaviors and } \\
\text { significantly fewer stress } \\
\text { behaviors for the } \\
\text { massaged group } \\
(p=0.05) \text {. } \\
\text { More mature motor } \\
\text { behaviors for the infants } \\
\text { that received massage } \\
\text { treatment }(p<0.005) \text {. }\end{array}$ \\
\hline Level of evidence $^{\mathrm{a}}$ & $2 b$ & $2 b$ & $2 b$ & $2 b$ \\
\hline
\end{tabular}

${ }^{a}$ Level of evidence is as defined by the Oxford Centre for Evidence-based Medicine_-Levels of Evidence (March 2009). Available at:

http://www.cebm.net/oxford-centre-evidence-based-medicine-levels-evidence-march-2009/ 
natural disasters, war, stressful settings, various medical conditions) (Field, 1995; White-Traut, 2004). All articles reviewed, including the RCTs, will be described according to subject.

\subsection{Effects on Maternal Distress and Mother-Infant Relationship}

Several studies on the Auditory, Tactile, Visual, and Vestibular (ATVV) intervention, which is actually a form of massage that involves moderate stroking, eye contact with, talking to, and rocking the infant, have resulted in positive preterm infant outcomes including increased alertness before and after feedings, more rapid progression from gavage to complete oral feedings, better weight gain, better growth, decreases in serum cortisol level, clearer behavioral cues, increased responsiveness to mothers, and earlier hospital discharge (Field, 1995; Holditch-Davis et al., 2014; White-Traut, 2004). In addition, mothers who provided ATVV for their infants showed more positive interactive behaviors, were more sensitive to their infants' behavioral cues, engaged in more behaviors that foster cognitive growth, and their anxiety and depression levels were reduced (Holditch-Davis et al., 2014; Matricardi et al., 2013; White-Traut, 2004).

ATVV is regarded as safe intervention for preterm infants, fullterm infants, and infants prenatally exposed to illicit substances, as tactile stimulation is vital to development of the central nervous system (White-Traut, 2004). However, tactile-only stimulation must be distinguished from multisensory interventions that include a tactile component, because tactile-only stimulation without social contact is associated with higher levels of stress, as measured via salivary cortisol, and it is also overstimulating for infants (White-Traut, 2004). For the above mentioned reasons, is recommended a moderate pressure massage in conjunction with human social contact that includes talking, eye-to-eye contact, and rocking (White-Traut, 2004).

An RCT study (Table 1) revealed that mothers who provided a form of massage for their preterm infants had a more rapid decline in depressive symptoms $(p<0.05)$, higher HOME scores (Inventory that measures the social-emotional and stimulation characteristics of the home environment), and less parenting stress (a form of massage only $\rightarrow p<0.001$ ) (Holditch-Davis et al., 2014). The study, however, presents limitations such as: large amount of missing values in some measures (e.g. visit diary), limited sample size and evidence of diffusion of the intervention (20\% - 30\% of Kangaroo Care and ATVV mothers and 58\% of control mothers engaged in a non-assigned intervention) (Holditch-Davis et al., 2014).

Another RCT (Table 1) showed that the intervention of joint observation method and infant massage was effective in the reduction of stress-role alteration in mothers with very preterm (VPT) infants in a Neonatal Intensive Care Unit (NICU) $(p<0.05)$, however, one of the limitations of the study (except for the relatively small sample size) was that it was not possible to establish which of these two previous mentioned components was more effective in reducing the parental stress levels (Matricardi et al., 2013).

In another pilot study (Table 1), adolescent mothers trained in infant massage had significantly lower depression scores than teen mothers without massage training $(p<0.05)$ (Oswalt et al., 2009). Additionally, teen mothers in the intervention group (infant massage) reported significantly more adaptive temperament of their infant than those in the control group $(p<0.05$ ) (Oswalt et al., 2009). Among the limitations of the study was the small sample size, a poor retention rate which allowed of no generalization of the above mentioned results, inability to monitor compliance with the massage intervention, the use of self-report measures and therefore subject to potential response bias, inadequate measure for depression assessment (by reason of the large variability found within the depression scores), and the unclearness of the relationship between infant development and maternal influence (Oswalt et al., 2009). The massage intervention exhibited: a medium effect size on feelings of physical contact with current relationships $(\mathrm{d}=0.59)$, a large effect size for parental stress, maternal perception of infant temperament, and positive feelings related to physical contact $(\mathrm{d}=0.92,1.34$, and 0.62$)$, and an also large effect size for both depression and maternal confidence ( $d=0.91$ and 1.10) (Oswalt et al., 2009).

\subsection{Effects on Cocaine-Exposed Preterm Infants}

In an RCT pilot study (Table 1) (Wheeden et al., 1993), cocaine-exposed preterm neonates who received massage showed significantly fewer stress behaviors $(p=0.05)$, and they exhibited more mature motor behaviors on the Brazelton examination at the end of the 10-day study period $(p<0.005)$ (Field, 1995; Wheeden et al., 1993). The study, however, presented limitations such as: lack of information on subject demographic variables (race and gender) and details on how the neonates were chosen for the study, lack of descriptive information on the 
assessment measures used in the study (the Postnatal Complications Scale and the Newfoundland Scale), and lack of identification of the specific complications that were alleviated by the massage intervention (Wheeden et al., 1993).

\subsection{Effects on Healthy Infants and Their Parents}

Infant massage facilitates parent-infant bonding and the development of warm, positive relationships, reduces stress responses to painful procedures (e.g. inoculations), reduces pain associated with teething and constipation, reduces colic, helps induce sleep, and effects positive feelings on parents while they are massaging their infants (Field, 1995).

\subsection{Effects on Depressed Mothers}

Preliminary data analysis of a study suggested that infant massage increased drowsiness and quiet sleep, reduced infants' latency to sleep, increased infants' vocalizations, reduced restlessness, improved mother's play behavior (became more age-appropriate) and mother's perception of their infant's temperament, and reduced infants' fussiness after the 2-week period (Field, 1995).

\subsection{Effects on Grandparent Volunteers as Massage Therapists}

In a study on training volunteer grandparents to give neglected and abused infants massage, preliminary data analyses suggested the following effects for the infants: 1 ) drowsiness and quiet sleep increased and activity decreased after the massage; 2) after 1 month of massage, alertness and tracking behaviors increased; and 3) behavior observations suggested increased activity, sociability, and soothability (Field, 1995). For the grandparent volunteers a data analysis revealed the following effects: 1 ) they reported less anxiety, fewer depression symptoms, and an improved mood after giving the massage; 2) their stress, which was measured by cortisol levels in their urine, decreased; 3) their lifestyle improved with more social contacts, fewer doctor visits, and fewer cups of coffee, and 4) they reported improvement in their self-esteem (Field, 1995).

\subsection{Effects on Asthmatic Children and Their Parents}

Data analyses of a study on the effects of infant massage on asthmatic children revealed the following: 1) the parents' anxiety decreased; 2) the children's self-reported anxiety levels decreased; 3) their mood improved; and 4) their cortisol levels decreased (Field, 1995). Over the 1-month period, the asthmatic children had fewer asthma attacks and they were able to breathe better, as determined by daily peak air flow readings (Field, 1995).

\subsection{Effects on Children with Diabetes and Their Parents}

In a study, which its purpose was to give parents a more positive role in their children's treatment by massaging them daily before bedtime, preliminary data analysis of pilot data on a sample of 13 children revealed the following effects: 1) immediately after the massage therapy sessions, parents' anxiety and depression levels were lower, and their children's anxiety and depression levels were reduced; 2) at the end of the 1-month period, the parents' insulin and food regulation scores improved, and the children's blood glucose levels decreased to the normal range (Field, 1995).

\section{Discussion}

Only 4 RCTs that evaluated the effect of infant massage were identified (Holditch-Davis et al., 2014; Matricardi et al., 2013; Oswalt et al., 2009; Wheeden et al., 1993). The following beneficial effects have been identified:

1) Mothers who provided a form of massage for their preterm infants had a more rapid decline in depressive symptoms, higher HOME scores, and less parenting stress; however, Kangaroo Care (KC) mothers showed a more rapid decline in worry than other mothers, and developmental maturity was higher for KC infants in comparison with the other groups (Holditch-Davis et al., 2014).

2) The intervention of joint observation method and infant massage was effective in the reduction of stress-role alteration in mothers with VPT infants in a NICU, still it was not possible to establish which of these two components was more effective in reducing the parental stress levels (Matricardi et al., 2013). 
3) Adolescent mothers trained in infant massage had significantly lower depression scores than teen mothers without massage training, and they reported significantly more adaptive temperament of their infant than those in the control group (Oswalt et al., 2009). Nevertheless, the use of self-report measures and therefore subject to potential response bias, and the poor retention rate allowed of no generalization of the above mentioned results (Oswalt et al., 2009).

4) Cocaine-exposed preterm neonates who received massage showed significantly fewer stress behaviors, and they exhibited more mature motor behaviors on the Brazelton examination (Wheeden et al., 1993). However, lack of information on subject demographic variables and details on how the neonates were chosen for the study, lack of descriptive information on the assessment measures used in the study, and lastly, lack of identification of the specific complications that were alleviated by the massage intervention, impose further research in order for the efficacy of the intervention to be established (Wheeden et al., 1993).

5) Infant massage had positive effects on: healthy infants and their parents, depressed mothers, grandparent volunteers as massage therapists, asthmatic children and their parents, and children with diabetes and their parents (Field, 1995).

According to the articles of this systematic review, infant massage is regarded as safe intervention for preterm infants (normal preterm infants, very preterm, brain-injured preterm infants), fullterm infants, infants prenatally exposed to illicit substances, and children with various medical conditions, as tactile stimulation is vital to development of the central nervous system (Field, 1995; White-Traut, 2004). However, tactile-only stimulation must be distinguished from multisensory interventions that include a tactile component, for tactile-only stimulation without social contact is associated with higher levels of stress, and it is also overstimulating for infants (White-Traut, 2004). Therefore, it is recommended a moderate pressure massage in conjunction with human social contact that includes talking, eye-to-eye contact, and rocking (White-Traut, 2004).

\section{Conclusion}

Massage therapy is one of the oldest touch therapies. It has been variously used for many conditions. Recent studies verify the beneficial role of infant massage for both mothers and their infants. Practicing infant massage helps in reducing anxiety, depression and stress, while it also affects the immune system, gain weight for the infant and hormones regulation. Infant massage is regarded as safe intervention for preterm infants, fullterm infants, infants prenatally exposed to illicit substances, and children with various medical conditions, as tactile stimulation is vital to development of the central nervous system. However, tactile-only stimulation must be distinguished from multisensory interventions that include a tactile component, for tactile-only stimulation without social contact is associated with higher levels of stress, and it is also overstimulating for infants.

As far as the limitations of this systematic review are concerned, we feel obliged to mention the small number of relative studies that have been selected. The study focused in 6 previous studies. Maybe a larger number of relative previous studies could have accounted for more interesting and differentiated findings. Moreover one of the study limitations is that it is focused only on randomized clinical trials rather than correlational or even theoretical approaches. It is possible that the analysis of a wider methodological approach studies base can lead to more spherical conclusions.

Future research on infant massage and its effects on immune function in infants with various medical conditions, such as cancer and Human Immunodeficiency Virus, using their parents as massage therapists, would be helpful as massage could also contribute to medical therapies.

\section{References}

Field, T. (1995). Massage Therapy for Infants and children. Journal of Developmental \& Behavioral Pediatrics, 16, 105-111. http://dx.doi.org/10.1097/00004703-199504000-00008

Holditch-Davis, D., White-Traut, R. C., Levy, J. A., O’Shea, T. M., Geraldo, V., \& David, R. J. (2014). Maternally Administered Interventions for Preterm Infants in the NICU: Effects on Maternal Psychological Distress and Mother-Infant Relationship. Infant Behavior \& Development, 37, 695-710. http://dx.doi.org/10.1016/j.infbeh.2014.08.005

Matricardi, S., Agostino, R., Fedeli, C., \& Montirosso, R. (2013). Mothers Are Not Fathers: Differences between Parents in the Reduction of Stress Levels after a Parental Intervention in a NICU. Acta Paediatrica, 102, 8-14. http://dx.doi.org/10.1016/j.infbeh.2014.08.005

Oswalt, K. L., Biasini, F. J., Wilson, L. L., \& Mrug, S. (2009). Outcomes of a Massage Intervention on Teen Mothers: A Pi- 
lot study. Pediatric Nursing, 35, 284-289, 317.

Wheeden, A., Scafidi, F. A., Field, T., Ironson, G., Valdeon, C., \& Bandstra, E. (1993). Massage Effects on Cocaine-Exposed Preterm Neonates. Journal of Developmental \& Behavioral Pediatrics, 14, 318-322. http://dx.doi.org/10.1097/00004703-199310000-00005

White-Traut, R. (2004). Providing a Nurturing Environment for Infants in Adverse Situations: Multisensory Strategies for Newborn Care. Journal of Midwifery \& Women's Health, 49, 36-41. http://dx.doi.org/10.1016/j.jmwh.2004.05.004 